\title{
Karakter Agronomi Beberapa \\ Varietas Tomat (Solanum lycopersicum) \\ Akibat Pemberian Ekstrak Lamtoro (Leucaena leucocephala L. )
}

\author{
Agronomic Characteristics of \\ Solanum lycopersicum MILL. \\ on Application of Leucaena leucocephala L. Extract
}

\author{
Elvira S. D ${ }^{1)}$, Muhamad Yusuf ${ }^{1)}$, dan Desi Yarnika ${ }^{2)}$ \\ ${ }^{1)}$ Program Studi Agroekoteknologi, Fakultas Pertanian, Universitas Malikussaleh \\ Kampus Cot Teungku Nie, Reuleut, Muara Batu Aceh Utara 24355, Indonesia \\ Emailelvira.fp@gmail.com \\ 2) Alumni
}

Diterima 10 Juli 2014; Dipublikasi 1 September 2014

\begin{abstract}
Abstrak
Penelitian bertujuan untuk mengevaluasi karakter agronomi beberapa varietas Solanum lycopersicum MILL. akibat pemberian ekstrak lamtoro (Leucaena leucocephala, L.) dengan dosis berbeda. Penelitian dilaksanakan menggunakan rancangan acak kelompok dengan tiga ulangan. Dua varietas yang dicobakan adalah Mawar dan Karina, sebagai faktor pertama. Ekstrak lamtoro terdiri dari kontrol, $300 \mathrm{cc} / 1,400 \mathrm{cc} / \mathrm{l}$, dan $500 \mathrm{cc} / \mathrm{l}$. Variabel yang diamati terdiri dari tinggi tanaman umur 15 dan 30 hari setelah tanam, jumlah bunga per dompolan, umur berbuah, jumlah bunga per dompolan per tanaman, dan berat buah. Hasil penelitian menunjukkan bahwa tinggi tanaman, umur berbuah, jumlah bunga per dompolan tiap tanaman dan berat buah sangat dipengaruhi oleh varietas. Sedangkan untuk pemberian ekstrak lamtoro, tidak ditemukan pengaruh pada setiap variabel pengamatan.
\end{abstract}

Kata kunci: ekstrak, lamtoro, Solanum lycopersicum., Leucaena leucocephala, L. Mawar, Karina.

\begin{abstract}
The research aimed to evaluate the agronomic characteristics of several varieties Solanum esculentum on various dose of lamtoro (Leucaena leucocephala, L.) extract. The research arranged in randomized complete block design with three replicate. There were two varieties, named Mawar and Karina, as the first factor. Extract of lamtoro were given on none as control, $300 \mathrm{cc} / 1,400 \mathrm{cc} / 1$, and $500 \mathrm{cc} / 1$. Variable observed were plant height on 15 and 30 day after planting (DAP), number of flower per branch, fruiting time, number of flower per branch on each plant, and fruit weigth. The result showed that plant height, fruitting time, number of flower per branch on each plant, and fruit weigth were affected significantly by variety. However, there were no significant affect found in all variable observed due to the extract application.
\end{abstract}

Keywords: extract, lamtoro, Solanum lycopersicum MILL., Leucaena leucocephala, L. Mawar, Karina.

\section{Pendahuluan}

Tomat (Solanum lycopersicum) merupakan salah satu tanaman hortikultura yang berasal dari Benua Amerika dan tersebar dari Amerika Tengah hingga Selatan. Di Indonesia, pengembangan tomat sudah diprioritaskan sejak tahun 1961. Produksi tomat di Indonesia mengalami peningkatan dari 0,64 juta ton pada tahun 2007 menjadi 0,70 ton pada tahun 2008 . Tingkat konsumsi tomat mengalami peningkatan dari $1,17 \mathrm{~kg} / \mathrm{kapita}$ pada tahun 2006 menjadi $2,09 \mathrm{~kg} / \mathrm{kapita}$ pada tahun 2007 (Ditjen Hortikultura, 2009). Konsumsi tomat tahun 2008 juga mengalami peningkatan menjadi 2,23 $\mathrm{kg} / \mathrm{kapita}$ dan pada tahun 2009 - 2010 kemudian menurun 1,97 kg/kapita. Angka ini kembali mengalami pening-katan ke 2,09 kg/kapita di tahun 2011 (BPS, 2011). Di level nasional, di tahun yang sama yaitu 2011, produksi tomat mencapai angka 953.046 ton yang kemudian menurun di tahun 2012 ke angka 893.504 ton. 
Namun di tahun 2013, produksi tomat kembali meningkat menjadi 992.780 ton (BPS, 2014).

Fluktuatifnya angka produksi ini dapat saja disebabkan oleh berbagai faktor terutama dalam budidaya. Penggunaan varietas yang tepat dan unggul akan dapat meningkatkan produksi apabila didukung oleh penggunaan input berupa pupuk secara tepat dosis dan tepat waktu.

Sampai saat ini telah banyak varietas tomat yang dihasilkan diantaranya adalah Mawar dan Karina. Varietas Mawar memiliki karakter buah berbentuk belimbing dan tekstur kulit buah mengkilat dengan rasa sedikit asam. Produksi per tanaman dapat mencapai $2-3 \mathrm{~kg}$. Varietas ini memiliki umur $70-75$ hari setelah tanam. Sedangkan varietas Karina, berbuah bulat dan agak lembek. Potensi hasil dapat mencapai $2-3$ $\mathrm{kg} /$ tanaman dengan masa hidup yang lebih singkat yaitu hanya 60 - 70 HST saja dibanding varietas Mawar.

Penggunaan pupuk yang tepat masih sering diabaikan oleh petani dalam praktek budidaya sehingga hasil yang didapat kurang maksimal. Seringkali petani tidak mampu memenuhi kebutuhan akan pupuk bagi tanaman yang bersumber dari pupuk buatan dikarenakan faktor harga dan terkadang kurangnya ketersediaan di pasaran. Hal ini dapat disiasati melalui substitusi pupuk buatan dengan pupuk organik yang berasal dari bahan alami di lingkungan sekitar. Salah satunya adalah lamtoro (Leucaena leucocephala, L.) yang dapat dijadikan pupuk hayati. Tanaman ini mengandung sejumlah unsur yang dibutuhkan oleh tanaman seperti $\mathrm{N}(2,0-4,3 \%), \mathrm{P}(0,2-$ $0,4 \%)$, dan K $(1,3-4,0 \%)$ (Sutanto dan Rachman, 2002). Selain itu lamtoro termasuk tanaman yang mudah didapat dengan sebaran hampir merata di wilayah Indonesia. Lamtoro banyak dimanfaatkan sebagai naungan dan sumber pakan ternak ruminasia. Peran lamtoro sebagai pupuk hayati tentu perlu dikaji lebih dalam terutama pada tanaman tomat.

\section{Metode Penelitian}

Penelitian dilaksanakan di Desa Babah Krueng Kecamatan Sawang Kabupaten Aceh Utara, dengan ketinggian tempat $200-300 \mathrm{~m}$ dpl. Penelitian dilaksanakan dari bulan September 2012 sampai Januari 2013. Bahan yang digunakan adalah benih tomat varietas Mawar dan Karina, tanah bagian top soil, dan ekstrak daun lamtoro. Penelitian menggunakan pola rancangan acak kelompok, 3 ulangan.

Faktor yang diamati adalah varietas yang terdiri dari V1 (Mawar) dan V2 (Karina); dan ekstrak daun lamtoro terdiri dari L0 (kontrol), L1 (300 cc/l air), L2 (400 cc/l air), dan L3 (500 cc/l air). Variabel yang diamati terdiri dari tinggi tanaman umur 15 dan 30 hari setelah tanam, jumlah bunga per dompolan, waktu berbunga, jumlah bunga per dompolan per tanaman, dan berat buah. Data dianalisis secara statistik menggunakan analisis keragamana rancang-an acak kelompok dua faktor. Perlakuan diuji menggunakan uji lanjtu Beda Nyata Terkecil (BNT) taraf 0.05 .

Pelaksanaan penelitian meliputi beberapa tahapan, diantaranya persemaian benih, persiapan ekstrak daun lamtoro, penanaman dalam polibag, pengaplikasian ekstrak daun lamtoro dan peme-liharaan serta pemanenan tanaman.

\section{Hasil dan Pembahasan}

\section{Tinggi tanaman}

Pengamatan tinggi tanaman akibat pengaruh berbedanya varietas dan pemberian ekstrak daun lamtoro pada umur 30 HST dapat di lihat pada Tabel 1 .

Tabel 1. Rerata tinggi tanaman pada umur 30 HST.

\begin{tabular}{lcc}
\hline \multirow{2}{*}{ Perlakuan } & \multicolumn{2}{c}{ Umur tanaman (HST) } \\
\cline { 2 - 3 } & 15 & 30 \\
\hline Varietas & & \\
- Mawar & $27.55 \mathrm{~b}$ & $81.35 \mathrm{a}$ \\
- Karina & $31.22 \mathrm{a}$ & $70.31 \mathrm{~b}$ \\
\hline Ekstrak daun lamtoro & & \\
- Kontrol & $29.10 \mathrm{a}$ & $76.57 \mathrm{a}$ \\
- 300 cc/l & $29.86 \mathrm{a}$ & $73.88 \mathrm{a}$ \\
- 400 cc/l & $29.21 \mathrm{a}$ & $77.46 \mathrm{a}$ \\
- 500 cc/l & $29.36 \mathrm{a}$ & $75.40 \mathrm{a}$ \\
\hline
\end{tabular}

Keterangan: angka yang diikuti huruf yang sama pada kolom yang sama menunjukkan tidak berbeda nyata pada uji BNT 0.05 .

Data pada Tabel 1 menunjukkan bahwa varietas berpengaruh sangat nyata terhadap tinggi tanaman umur 15 dan 30 HST. Varietas Karina memiliki tinggi tanaman tertinggi untuk kedua umur pengamatan $(27.55 \mathrm{~cm} ; 81.35 \mathrm{~cm})$ dibandingkan dengan varietas Mawar. Pemberian ekstrak daun lamtoro tidak memberikan pengaruh nyata secara statistik, 
namun dari data tabel terlihat bahwa dosis 300 $\mathrm{cc} / \mathrm{l}$ air menghasilkan tinggi tanaman lebih tinggi dari dosis lain.

Kondisi ini dimungkinkan oleh adanya interaksi faktor genetik dengan faktor pendukung pertumbuhan. Perbedaan respon genotipe pada ber-bagai lingkungan hidup akan menyebabkan penam-pilan fenotipe yang berbeda pada setiap varietas (Harjadi, 1998). Pemberian ekstrak daun lamtoro menunjukkan respon tinggi tanaman yang tidak signifikan. Hal ini dapat disebabkan oleh lambatnya ketersediaan unsur hara dari ekstrak daun lamtoro itu sendiri dan juga metode pengaplikasian yang kurang sesuai melalui tanah. Sarief (2005) penyerapan unsur hara akan lebih efektif bila diaplikasikan melalui daun dibandingkan melalui akar.

\section{Jumlah bunga per dompolan}

Tabel 2 menunjukkan bahwa tidak adanya perbedaan pada variabel yang diamati akibat penggunaan varietas yang berbeda dan pemberian ekstrak daun lamtoro secara statistik. Namun, varietas Mawar menghasilkan jumlah bunga per dompolan lebih banyak dibandingkan varietas Karina. Adanya perbedaan genotipe dari kedua varietas tentu saja akan menghasilkan karakter agronomi berbeda di setiap lingkungan tumbuh. Genotipe suatu tanaman merupakan faktor utama dalam setiap adaptasi pertumbuhan (Villareal, 1979).

Dosis ekstrak daun lamtoro sebanyak 300 cc/l air menghasilkan jumlah bunga per dompolan lebih banyak dibandingkan dengan dosis lainnya (Tabel 2). Namun, data ini tidak menunjukkan pengaruh yang signifikan secara statistik. Ketersediaan unsur hara yang dapat diserap oleh tanah merupakan salah satu faktor yang mempengaruhi tingkat produksi suatu tanaman (Saifuddin, 1986).

\section{Umur berbuah}

Varietas Mawar mengindikasikan umur berbuah yang lebih cepat dibandingkan varietas Karina (Tabel 2). Sifat unggul suatu varietas dimungkinkan akan muncul apabila dibudidayakan sesuai dengan yang dibutuhkan oleh varietas tersebut (Chairani, 2008). Meskipun secara statistik tidak signifikan, namun dosis ekstrak daun lamtoro sebanyak $300 \mathrm{cc} / \mathrm{l}$ air dapat mempercepat umur berbuah dari kedua varietas yang dicobakan. Pada tanaman kacang tanah, pemberian pupuk hijau lamtoro sebanyak 10 ton/ha mampu meningkatkan hasil sebesar 41.94\% (Listyarini, 2010).

\section{Jumlah bunga per dompolan per tanaman}

Penggunaan varietas memberikan pengaruh sangat berbeda terhadap jumlah buah per dompolan per tanaman (Tabel 2).

Tabel 2. Rerata jumlah bunga per dompolan dan umur berbuah.

\begin{tabular}{lll}
\hline \multicolumn{1}{c}{ Perlakuan } & $\begin{array}{c}\text { Jumlah } \\
\text { bunga per } \\
\text { dompolan }\end{array}$ & $\begin{array}{c}\text { Umur } \\
\text { berbuah } \\
\text { (HST) }\end{array}$ \\
\hline Varietas & & \\
- Mawar & $5.16 \mathrm{a}$ & $30.97 \mathrm{~b}$ \\
- Karina & $4.98 \mathrm{a}$ & $37.08 \mathrm{a}$ \\
\hline Ekstrak daun lamtoro & & \\
- Kontrol & $4.91 \mathrm{a}$ & $33.89 \mathrm{a}$ \\
- 300 cc/l & $5.24 \mathrm{a}$ & $35.00 \mathrm{a}$ \\
- 400 cc/l & $4.95 \mathrm{a}$ & $33.61 \mathrm{a}$ \\
- 500 cc/l & $5.18 \mathrm{a}$ & $33.61 \mathrm{a}$ \\
\hline
\end{tabular}

Keterangan: angka yang diikuti huruf yang sama pada kolom yang sama menunjukkan tidak berbeda nyata pada uji BNT 0.05 .

Namun pemberian ekstrak daun lamtoro tidak memberikan pengaruh terhadap variabel ini. Dalam hal ini, varietas Mawar menghasilkan jumlah buah per dompolan per tanaman terbanyak dibandingkan varietas Karina. Kondisi ini sesuai dengan data pada Tabel 2 yang menunjukkan bahwa varietas Mawar juga memiliki jumlah bungan per dompolan yang relatif lebih banyak bila dibandingkan dengan varietas Karina. Tanggap suatu varietas terhadap faktor lingkungan dapat terjadi berdasarkan faktor genetik misalnya kemampuan adaptasi akibat iklim dan sebagainya (Mangoendidjojo, 2003).

Meskipun secara statistik tidak berpengaruh nyata akibat pemberian ekstrak daun lamtoro, namun berdasarkan rata-ratanya, dosis $400 \mathrm{cc} / \mathrm{l}$ air nampaknya dapat meningkatkan jumlah buah per dompolan pada setiap tanaman tomat (Tabel 3).

\section{Berat buah}

Berdasarkan data pada Tabel 3, seperti halnya jumlah buah per dompolan setiap tanaman, varietas Mawar juga memperlihatkan rata-rata buah yang lebih berat dibandingkan dengan varietas Karina. Produktivitas suatu 
tanaman seperti yang dinyatakan oleh Sarief (2005) akan dipengaruhi oleh varietas yang digunakan, pengelolaan tanah dan tanaman, serta nutrisi yang cukup dan seimbang. Hal serupa pernah dikemukan juga sebelumnya oleh Darjanto dan Satifah (1984) yang menyatakan bahwa setiap tanaman akan mengalami pengaruh dari luar yang sama sehingga faktor utama yang membedakan hasil adalah varietas.

Sama hal nya pada jumlah buah per dompolan per tanaman, ekstrak daun lamtoro sebanyak $400 \mathrm{cc} / \mathrm{l}$ air meski tidak signifikan secara statistik, tetap menunjukkan hasil yang lebih tinggi daripada dosis yang lain. Kemungkinan yang terjadi adalah tanaman belum sepenuhnya mampu menyerap unsur hara dari ekstrak yang diberikan.

Tabel 3. Rerata jumlah buah per dompolan per tanaman dan berat buah.

\begin{tabular}{lll}
\hline \multicolumn{1}{c}{ Perlakuan } & $\begin{array}{c}\text { Jumlah } \\
\text { buah per } \\
\text { dompolan/ } \\
\text { tanaman }\end{array}$ & $\begin{array}{c}\text { Berat } \\
\text { buah }\end{array}$ \\
\hline Varietas & & \\
- Mawar & $2.73 \mathrm{a}$ & $529.83 \mathrm{a}$ \\
- Karina & $1.74 \mathrm{~b}$ & $347.29 \mathrm{~b}$ \\
\hline Ekstrak daun lamtoro & & \\
- Kontrol & $2.05 \mathrm{a}$ & $409.04 \mathrm{a}$ \\
- 300 cc/1 & $2.00 \mathrm{a}$ & $459.15 \mathrm{a}$ \\
- 400 cc/l & $2.71 \mathrm{a}$ & $467.48 \mathrm{a}$ \\
- 500 cc/l & $2.17 \mathrm{a}$ & $418.21 \mathrm{a}$ \\
\hline
\end{tabular}

Keterangan: angka yang diikuti huruf yang sama pada kolom yang sama menunjukkan tidak berbeda nyata pada uji BNT 0.05.

Sebagaimana diketahui bahwa penggunaan jenis pupuk, dosis, cara dan waktu aplikasi yang tepat akan mempengaruhi respon suatu tanaman (Tisdale dan Nelson, 1993; dan Marschner, 1995).

\section{Kesimpulan}

Varietas Mawar memperlihatkan respon yang lebih baik dibandingkan varietas Karina terhadap tinggi tanama umur 15 dan 30 HST, jumlah bunga per dompolan, umur berbuah, jumlah bunga per dompolan per tanaman dan berat buah. Pemberian ekstrak daun lamtoro sejauh ini belum memberikan respon yang nyata terhadap semua peubah yang diamati.

\section{Daftar Pustaka}

Badan Pusat Statistik. 2011. Survei Sosial Ekonomi Nasional, Pengeluaran dan Konsumsi Penduduk Indonesia. Jakarta.

Badan Pusat Statistik. 2014. Survei Sosial Ekonomi Nasional, Pengeluaran dan Konsumsi Penduduk Indonesia. Jakarta.

Chairani, H. 2008. Teknik Budidaya Tanaman Jilid 1. Direktorat Pembinaan Sekolah Menengah dan Kejuruan. Jakarta.

Ditjen Hortikultura. 2009. Produksi Tanaman Sayuran di Indonesia Periode 2003 - 2008. http://www.hortikultura.deptan.go.id. (8 Oktober 2009).

Darjanto dan Satifah, S. 1984. Pengetahuan Dasar Biologi Bunga dan Teknik Penyerbukan Silang Buatan. Penerbit PT. Gramedia. Jakarta.

Harjadi, S. 1998. Pengaruh Perbedaan Bahan Stimulator Terhadap Bahan Organik (sifat fisik kompos). Pusat Studi Indonesia. Jakarta.

Listyarini, D. 2010. Pemanfaatan Beberapa Pupuk Hijau Dalam Penurunan Kepadatan Ultisol dan Produksi Kacang Tanah. http://www.diahlistyarini.blogspot.com.unt uk-perbaikan.htm. (15 April 2013).

Mangoendidjojo, W. 2003. Dasar-dasar Pemuliaan Tanaman. Kanisius. Yogyakarta.

Saifuddin, A. 1986. Pupuk Organik Kompos dan Sampah. Humaniora Utama Press. Bandung.

Sarief, E. S. 2005. Kesuburan dan Pemupukan Tanah Pertanian. Pustaka Buana. Bandung.

Sutanto, R. 2002. Penerapan Pertanian Organik: Pemasyarakatan dan Pengembangannya. Kanisius. Yogyakarta.

Tisdale, S. L., dan Nelson, W. L. 1993. Soil Fertility and Fertiliser. 3rd Edition. New York.

Villareal, R. L. 1979. Tomato Production In The Tropics Problem and Progress. 1st International Symposium on Tropical Tomato. Shanhva, Taiwan. 